05.1;05.3;06.5;15.2

\title{
Эффект памяти тройной формы полиуретанового композиционного материала
}

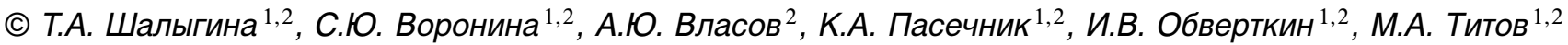 \\ ${ }^{1}$ Сибирский государственный университет науки и технологий им. акад. М.Ф. Решетнёва, Красноярск, Россия \\ ${ }^{2}$ Федеральный исследовательский центр „Красноярский научный центр СО РАН“, Красноярск, Россия \\ E-mail: leonova.ta@inbox.ru
}

Поступило в Редакцию 18 февраля 2020 г.

В окончательной редакции 2 апреля 2020 г.

Принято к публикации 22 июля 2020 г.

\begin{abstract}
Исследовано влияние аппретирующего слоя углеродных волокон на возникновение эффекта памяти тройной формы полиуретанового углепластика. С помощью термомодулированной дифференциальной сканирующей калориметрии определены структурные изменения образца полиуретана, армированного аппретированным углеволокном. Установлено влияние протекания механизма диффузионной адгезии на термомеханические характеристики эффекта памяти тройной формы полиуретанового композиционного материала.
\end{abstract}

Ключевые слова: эффект памяти тройной формы, механизм диффузионной адгезии, аппрет, углепластик, полиуретан, дифференциальная сканирующая калориметрия с температурной модуляцией.

DOI: 10.21883/PJTF.2020.20.50156.18251

Эффект памяти тройной формы (ЭПТФ) полимерных материалов - частный случай проявления классического эффекта памяти двойной формы, характеризуемый возможностью „запоминать“ дополнительную временную форму. Материалы с ЭПТФ могут осуществлять двухуровневые трансформации, соответствующие различным значениям температурного воздействия, и позволяют решать более сложные задачи во многих областях науки и техники. Появление ЭПТФ у полимерных материалов обусловлено прежде всего содержанием в их структуре определенного соотношения низкотемпературной (гибкой) и высокотемпературной (жесткой) молекулярной фаз $[1,2]$. Именно жесткая фаза отвечает за реализацию и фиксацию промежуточной формы при охлаждении ниже ее температурного перехода [3-5]. Поэтому задачей настоящей работы является увеличение доли жесткой молекулярной фазы в структуре полиуретановой матрицы, существенное преобладание гибкой фазы в которой накладывает ограничение на проявление ЭПТФ. За основу был выбран тот факт, что при производстве углеродного волокна, который является армирующим материалом в исследуемом образце, его поверхность покрывают полимерным аппретом. Таким образом, при изготовлении полиуретанового углепластика на границе раздела двух полимеров (в данном случае полимерного аппрета и полиуретанового связующего) может протекать механизм диффузионной адгезии, способствующий образованию переходного слоя с повышенной плотностью упаковки [6]. Подвижность сегментов полиуретановой матрицы, вовлеченных в диффузионный процесс, может снижаться либо за счет чисто физического ограничения, либо за счет образования физических связей с молекулярными цепями полимерного аппрета, при этом смещается соотношение гибких и жестких сегментов в сторону последних, что способствует проявлению ЭПТФ.

В качестве объектов исследования влияния аппретирующего слоя углеродных волокон на возникновение ЭПТФ выступали следующие образцы: 1) полиуретан, армированный тремя слоями биаксиальной ткани на основе аппретированных углеродных волокон (ПУа); 2) полиуретан, армированный тремя слоями биаксиальной ткани с предварительно удаленным с поверхности углеродных волокон аппретирующим слоем(ПУб/а); 3) неармированный полиуретан (ПУн/а). Подробное описание образца ПУа опубликовано в работе [7]. Аппретирующий слой с поверхности углеродных волокон был удален посредством отжига в муфельной печи при $400^{\circ} \mathrm{C}$ в течение $10 \mathrm{~min}$.

Калориметрические измерения в режиме температурной модуляции теплового потока образцов были выполнены с помощью дифференциального сканирующего калориметра DSC25 производства TA Instruments (США) в стандартных алюминиевых тиглях в атмосфере чистого $\mathrm{N}_{2}$ при скорости потока $70 \mathrm{ml} / \mathrm{min}$. Модуляция теплового потока была осуществлена по синусоиде с периодом $60 \mathrm{~s}$ и амплитудой $\pm 1^{\circ} \mathrm{C}$. Первый нагрев осуществлялся до $115^{\circ} \mathrm{C}$ со скоростью $10^{\circ} \mathrm{C} / \mathrm{min}$.

Исследование термомеханического цикла ЭПТФ образцов проводилось с использованием трехточечного изгибающего зажима термомеханического анализатора (TMA) Q400ЕМ производства TA Instruments (США). Измерения выполнялись в режиме регулируемой изгибающей нагрузки и изменяющейся температуры по заданной программе с одновременным измерением про- 


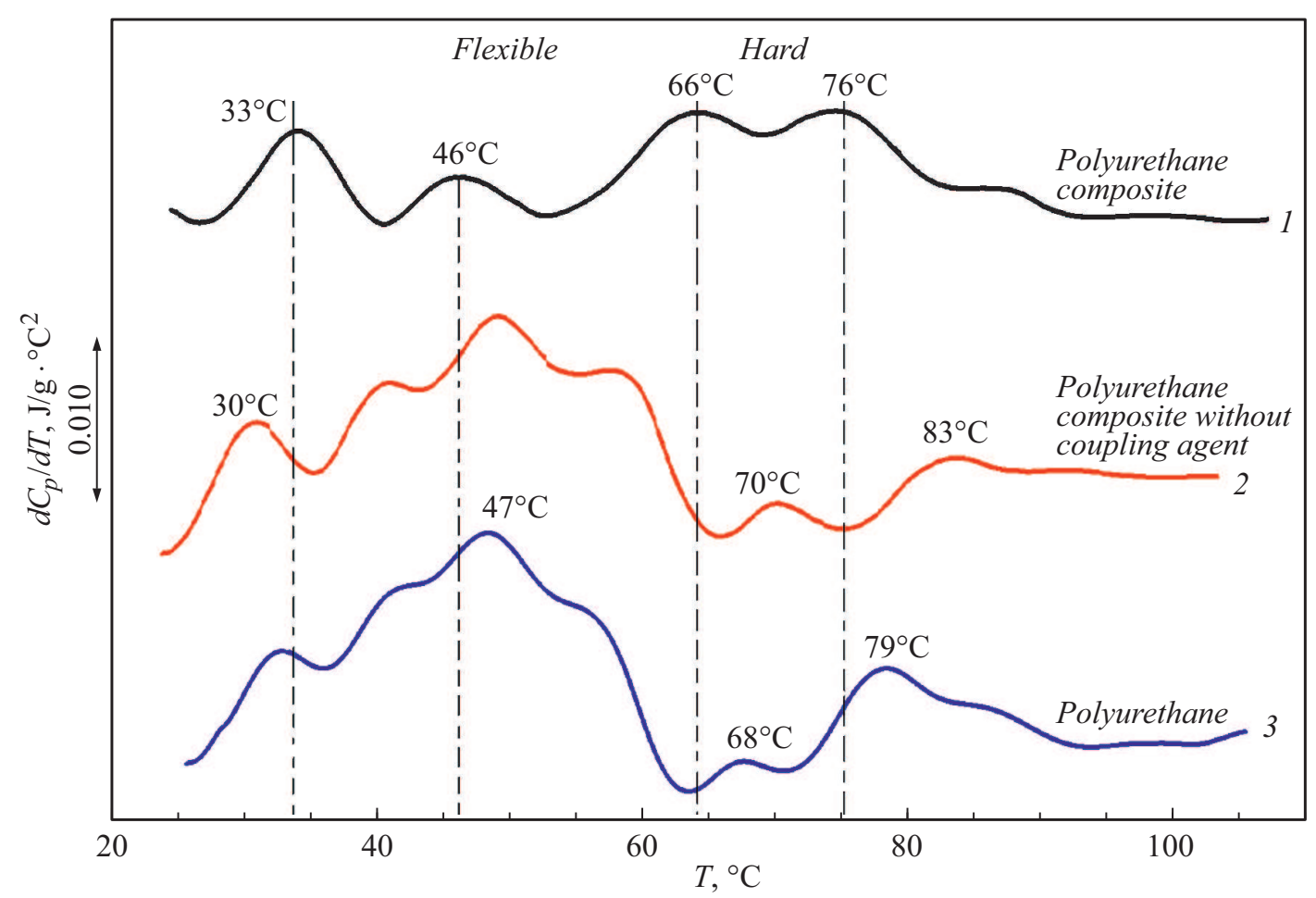

Рис. 1. Температурная зависимость $d C_{p} / d T$ образцов ПУа $(1)$, ПУб/а (2) и ПУн/а (3) при первом нагреве.

дольного перемещения образца. Образцы представляли собой бруски размером $10 \times 1.22 \times 0.72 \mathrm{~mm}$.

Проведение калориметрических измерений в режиме модуляции теплового потока позволяет получить сигнал обратимого теплового потока, отражающий ход изменения теплоемкости в зависимости от температуры $\left(C_{p}(T)\right)$. На кривой температурной зависимости первой производной теплоемкости по температуре $\left(d C_{p} / d T(T)\right)$ значения максимумов пиков можно считать температурами стеклования $\left(T_{g}\right)$, поскольку они соответствуют температурам, при которых скорость изменения теплоемкости (обратимого теплового потока) имеет локальный максимум [8-10]. Если проводить калориметрические измерения при первом нагреве, когда структура полиуретановой матрицы характеризуется высокой степенью фазового разделения, то можно получить индивидуальные калориметрические сигналы от сегментов гибкой и жесткой молекулярных фаз. На полученных кривых $d C_{p} / d T(T)$ для образцов ПУб/а и ПУн/а можно выделить по четыре основных пика, характеризующих тепловой переход в высокоэластическое состояние гибкой молекулярной фазы со значениями $T_{g 1} \approx 30^{\circ} \mathrm{C}$ и $T_{g 2} \approx 47^{\circ} \mathrm{C}$ и жесткой молекулярной фазы с $T_{g 3} \approx 70^{\circ} \mathrm{C}$ и $T_{g 4} \approx 80^{\circ} \mathrm{C}$ (рис. 1 , кривые 2,3 ). На кривой $d C_{p} / d T(T)$ для образца ПУа наблюдаются заметное уменьшение площади пика для теплового перехода гибкой молекулярной фазы с $T_{g 2} \approx 46^{\circ} \mathrm{C}$ и увеличение площади пиков для теплового перехода жесткой молекулярной фазы с $T_{g 3} \approx 66^{\circ} \mathrm{C}$ и $T_{g 4} \approx 76^{\circ} \mathrm{C}$ (рис. 1 , кривая 1). На основе полученных данных можно заклю- чить, что наличие аппретирующего слоя на поверхности армирующих углеродных волокон вызывает увеличение доли жесткой молекулярной фазы.

Термомеханическое исследование ЭПТФ подразумевает добавление этапов реализации и фиксации промежуточного деформированного состояния в процедуру, описанную в нашей предыдущей работе [7]. Подбор температурной программы был осуществлен с использованием калориметрических данных о значениях температур тепловых переходов $\left(T_{g}\right)$ исследуемых образцов (рис. 1). Схематическое представление данной методики с использованием трехточечного изгибающего зажима приведено на рис. 2 и характеризуется восемью этапами: этап 1 - нагревание образца до температуры $T_{\text {prog } 1} \geq T_{g 4}$, при которой осуществлялась реализация промежуточного деформированного состояния образца некоторым постоянным усилием $\left(\sigma_{m 1}\right)$; этап 2 - фиксация промежуточного деформированного состояния в процессе охлаждения до температуры $T_{g 2} \leq T_{\text {low } 1}<T_{g 3}\left[{ }^{\circ} \mathrm{C}\right]$ при постоянном значении напряжения $\sigma_{m 1}$; этап 3 - полная разгрузка образца; этап $4-$ повторное деформирование образца при значении напряжения $\sigma_{m 2}>\sigma_{m 1}$ и $T_{p r o g}=T_{l o w 1}$; этап $5-$ охлаждение образца до температуры $T_{\text {low } 2}<T_{g 1}$ (транспортировочной); этап 6 - полная разгрузка образца; этап 7 восстановление промежуточной формы при нагревании образца до температуры, равной $T_{r e c 1}=T_{l o w 1}$; этап $8-$ восстановление исходной формы при нагревании образца до температуры, равной $T_{r e c 2}>T_{g 4}$. 


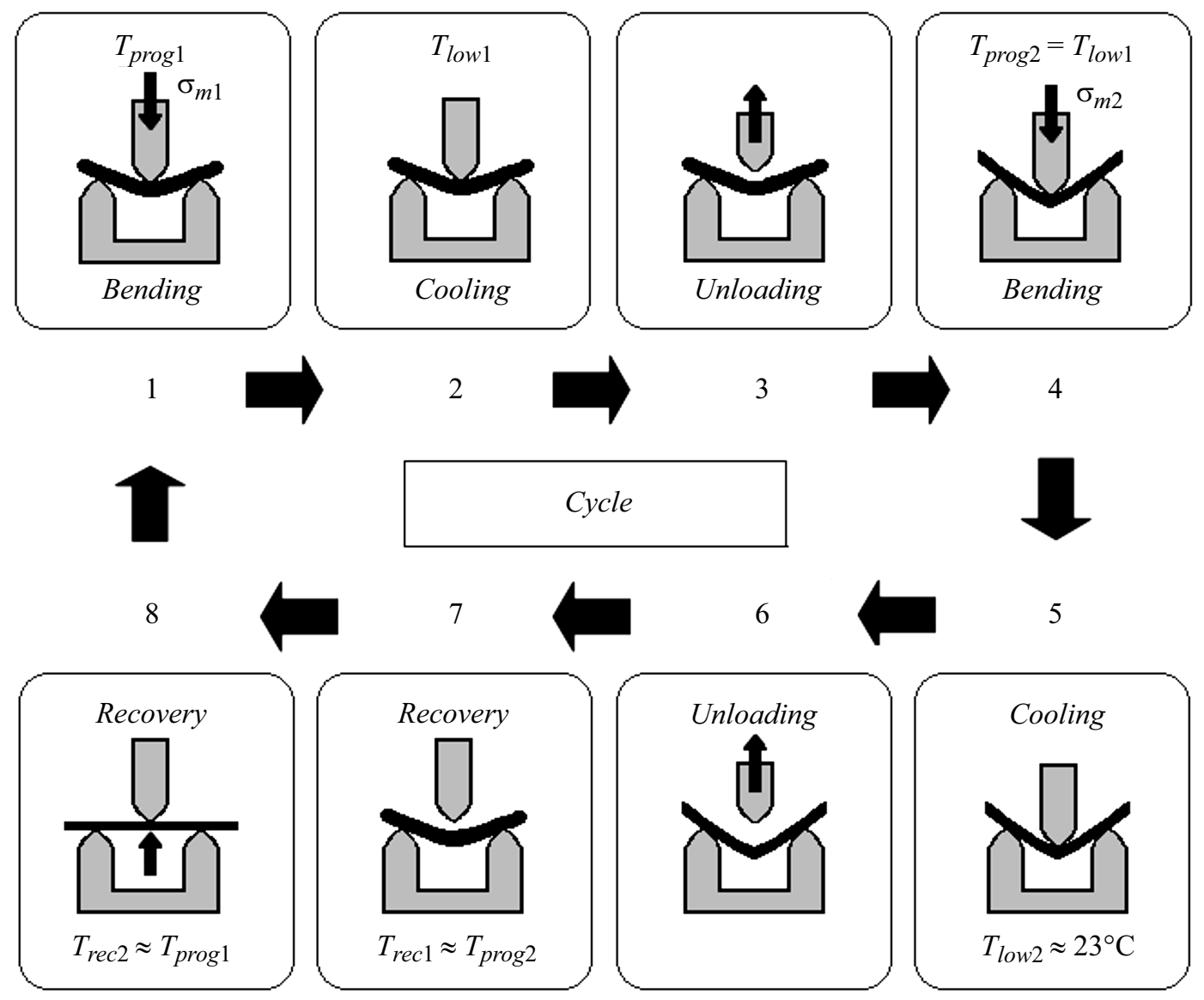

Рис. 2. Схематическое изображение методики реализации и фиксации промежуточного и конечного деформированного состояния образца с помощью трехточечного изгибающего зажима термомеханического анализатора.

Для количественной оценки ЭПТФ были определены коэффициенты восстановления $\left(R_{r}\right)$ и фиксации $\left(R_{f}\right)$ как для промежуточной, так и для конечной формы с помощью формул [11]:

$$
R_{r}=\frac{\varepsilon_{m(n)}-\varepsilon_{p(n)}}{\varepsilon_{m(n)}} \cdot 100 \%,
$$

где $n-$ порядковый номер этапа формирования промежуточной (1) или конечной (2) формы, $\varepsilon_{m}$ - значение общей деформации, определяемой как сумма мгновенной упругой $\varepsilon_{l}$ и запаздывающей высокоэластической деформации $\varepsilon_{c}\left(\varepsilon_{m}=\varepsilon_{l}+\varepsilon_{c}\right), \varepsilon_{p}-$ необратимая пластическая деформация;

$$
R_{f}=\frac{\varepsilon_{u(n)}}{\varepsilon_{m(n)}} \cdot 100 \%,
$$

где $\varepsilon_{u}$ - деформация, установившаяся в результате мгновенного восстановления некоторой части структурных единиц после снятия нагрузки $\sigma_{m 1}$ и $\sigma_{m 2}$ на этапах 3 и 6. Здесь важно отметить, что при расчете коэффициента восстановления промежуточной формы $\left(R_{r 1}\right)$ за $\varepsilon_{m 1}$ объективно следует принять $\varepsilon_{u 1}$, так как именно это значение характеризует установившуюся промежуточную форму на этапе 3 после разгрузки образца и восстановления некоторой части изгибной деформации.
Рассчитанные значения коэффициентов фиксации и восстановления промежуточной формы образцов

\begin{tabular}{c|c|c}
\hline Образец & $R_{f 1}, \%$ & $R_{r 1}, \%$ \\
\hline ПУа & 59 & 98.8 \\
ПУб/a & 48.9 & $125^{*}$ \\
ПУН/a & 61 & $148^{*}$
\end{tabular}

Примечание. * Значения указывают на плавное восстановление исходной формы уже на первой стадии нагрева до $T_{r e c 1}$.

На рис. 3, $а$ представлены ТМА-кривые, описывающие реализацию и фиксацию промежуточной и конечной форм образца ПУа. Как видно из кривой зависимости относительной деформации от времени, после снятия нагрузки в конце этапа 3 образец мгновенно восстановил одну треть приобретенной изгибной деформации. Связано это с тем, что при температуре $T_{\text {prog } 1}=80^{\circ} \mathrm{C}$ в процесс деформирования (реализации промежуточной формы) вовлечены и гибкие, и жесткие сегменты, находящиеся в высокоэластическом состоянии. После охлаждения до температуры $55^{\circ} \mathrm{C}$ жесткие сегменты перешли в стеклообразное состояние, зафиксировав часть де- 

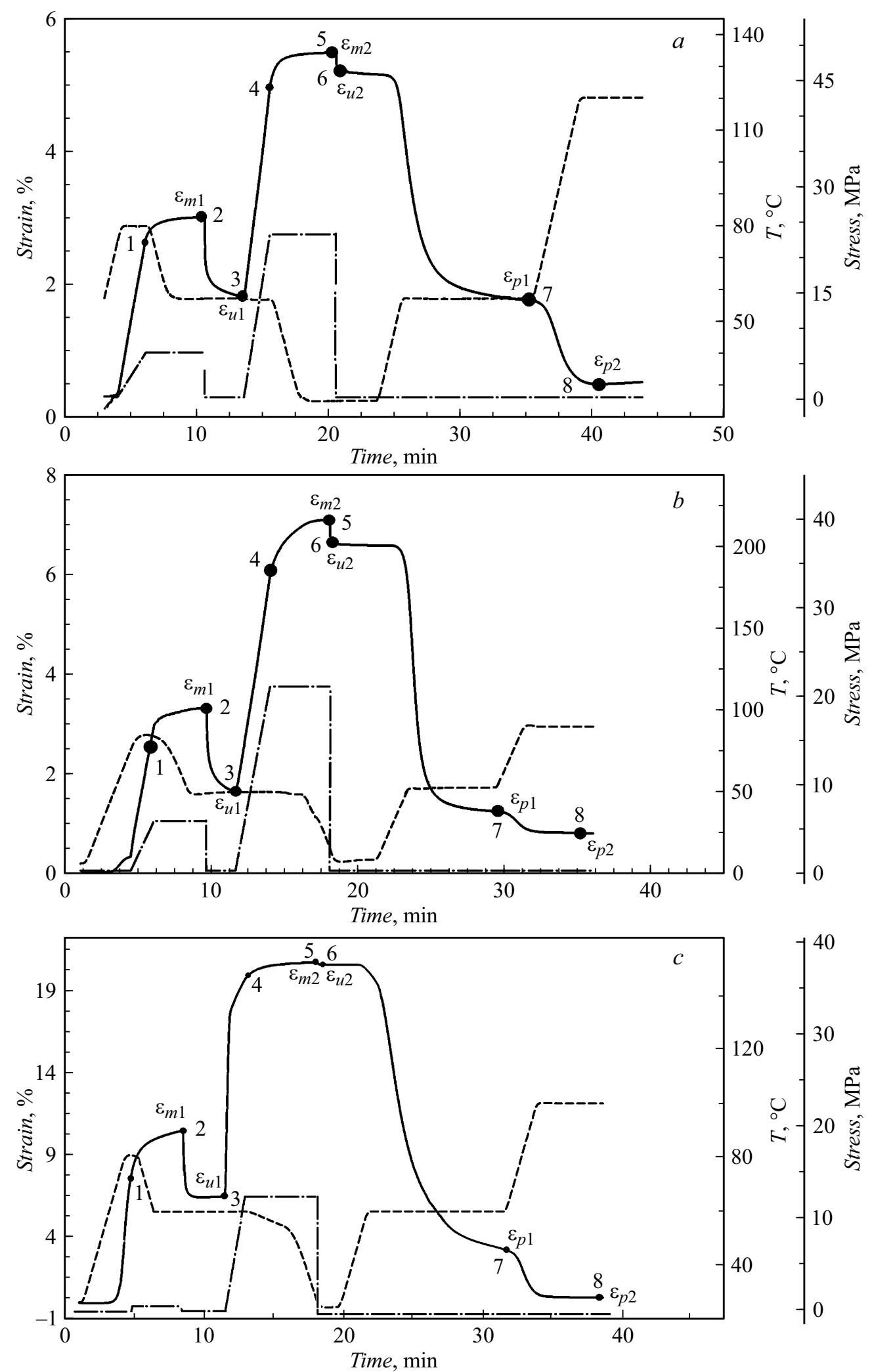

Рис. 3. Термомеханические кривые деформации (сплошная кривая), температуры (штриховая кривая) и напряжения (штрихпунктир) в зависимости от времени, описывающие ЭПТФ образцов. $a-$ ПУа, $b-$ ПУб/а, $c-$ ПУн/а. Цифры $1-8$ соответствуют этапам, представленным на рис. 2. 
формации, так как это значение находится за пределами их теплового перехода. Однако это значение также лежит в диапазоне высокоэластического состояния гибких сегментов, поэтому после снятия нагрузки произошло восстановление их вытянутой формы, приобретенной в конце этапа 1 при деформировании, в исходную свернутую. Коэффициент фиксации промежуточной формы $\left(R_{f 1}\right)$, рассчитанный по формуле $(2)$, составил $59 \%$. При повторном деформировании, но уже с бо́льшим значением напряжения удалось реализовать конечную форму образца. После снятия нагрузки в конце этапа 6 значение коэффициента фиксации конечной формы $\left(R_{f 2}\right)$ составило 95\%. На этапе 7 при $55^{\circ} \mathrm{C}$ произошло восстановление промежуточной формы, в большей степени за счет перехода в высокоэластическое состояние гибких сегментов, при этом значение $R_{r 1}$, рассчитанное по формуле (1), составило 98.8\%. Дальнейшее нагревание образца до $115^{\circ} \mathrm{C}$ привело к тепловому переходу в высокоэластическое состояние жестких сегментов и восстановлению исходной формы образца с $R_{r 2}=97 \%$. Рассчитанные значения $R_{f 1}$ и $R_{r 1}$ для образцов ПУа, ПУб/а и ПУн/а представлены в таблице. Кроме того, для образцов ПУб/а и ПУн/а значение восстановившейся изгибной деформации на 25 и 48\% соответственно превышает значение, характеризующее промежуточную форму (рис. $3, b, c)$.

Таким образом, было установлено, что наличие полимерного аппретирующего слоя на поверхности углеродных волокон способствует протеканию механизма диффузионной адгезии полиуретанового связующего, приводящего к изменению его структуры. По результатам калориметрии такое изменение характеризуется увеличением доли жесткой молекулярной фазы за счет уменьшения подвижности сегментов гибкой фазы, вовлеченных в диффузионный процесс. Это поспособствовало возникновению ЭПТФ с высокими показателями $R_{r}$ и $R_{f}$. Дальнейшее изучение зависимости протекания механизма диффузионной адгезии полиуретановой матрицы от состава аппретирующего слоя углеродных волокон позволит разработать концепцию получения полимерного композиционного материала с контролируемыми характеристиками ЭПТФ.

\section{Финансирование работы}

Исследование выполнено при финансовой поддержке Российского фонда фундаментальных исследований в рамках научного проекта № 19-33-90166.

\section{Конфликт интересов}

Авторы заявляют, что у них нет конфликта интересов.

\section{Список литературы}

[1] Wang L., Yang X., Chen H., Gong T., Li W., Yang G., Zhou Sh. // ACS Appl. Mater. Interfaces. 2013. V. 5. P. 10520 10528.

[2] Bellin I., Kelch S., Langer R., Lendlein A. // Proc. Natl. Acad. Sci. USA. 2006. V. 103. P. 18043-18047.

[3] Lu H., Wang X., Yu K., Fu Y.Q., Leng J. // Smart Mater. Struct. 2019. V. 28. P. 025031.

[4] Cuevas J.M., Rubio R., German L., Laza J.M., Vilas J.L., Rodriguez M., Leon L.M. // Soft Matter. 2012. V. 8. P. 4928 4935.

[5] Li J., Xie T. // Macromolecules. 2011. V. 44. P. 175-180.

[6] Липатов Ю.С. Физическая химия наполненных полимеров. М.: Химия, 1977. $304 \mathrm{c}$

[7] Шалыгина Т.А., Воронина С.Ю., Власов А.Ю., Пасечник К.А., Обверткин И.В. // Письма в ЖТФ. 2019. Т. 45. B. 9. C. $32-35$.

[8] Masson J.F., Polomark G.M. // Thermochim. Acta. 2001. V. 374. P. 105-114.

[9] Wunderlich B., Boiler A., Okazaki I., Ishikiriama K. // Thermochim. Acta. 1997. V. 304. P. 125-136.

[10] Miwa Y., Usami K., Yamamoto K., Sakaguchi M., Sakai M., Shimada S. // Macromolecules. 2005. V. 38. P. 2355-2361.

[11] Xie T. // Nature. 2010. V. 464. P. 267-270. 